\title{
Preparation and Characterization of Cellulose Composite Hydrogels From Tea Residue and Single-Walled Carbon Nanotube Oxides and Its Potential Applications
}

\author{
Zhijun Liu and Dianxin Li* \\ Guangdong Polytechnic of Science and Trade, Guangzhou, China
}

Hydrogels were prepared from tea cellulose with the addition of single-walled carbon nanotube oxides in 1-allyl-3-methylimidazolium chloride. Single-walled carbon nanotube oxides/tea cellulose hydrogels (TCH-SWNTs) were characterized by Fourier transform infrared, x-ray diffraction, texture profile analysis, and thermogravimetric analysis. The adsorption capacity of methylene blue using the prepared hydrogels was also investigated. The hydrogels exhibited greater thermal stability and intensive textural property with the addition of single-walled carbon nanotube oxides. Compared with undoped TCHs, the weight loss peak moved from 280 to $323^{\circ} \mathrm{C}$, and the values of hardness, fracturability, gumminess, and resilience were 8.4, 5.3, 10.8, and 1.9,

Edited by:

Yi Cao,

Xiangtan University, China

Reviewed by:

Leiqing Pan,

Nanjing Agricultural University, China Jiahong Wang

Nanjiing Forestry University, China

${ }^{*}$ Correspondence:

Dianxin L

Idx2008403@126.com

Specialty section: This article was submitted to

Polymer Chemistry, a section of the journal

Frontiers in Chemistry

Received: 10 January 2021 Accepted: 08 April 2021

Published: 04 May 2021

Citation:

Liu Z and Li D (2021) Preparation and Characterization of Cellulose

Composite Hydrogels From Tea Residue and Single-Walled Carbon Nanotube Oxides and Its Potential Applications. Front. Chem. 9:651566. doi: 10.3389/fchem.2021.651566 respectively, times higher than that of TCHs. As an absorbent of methylene blue, TCH-SWNTs accorded to a pseudo-second-order kinetic model, good adsorption capacity $(13.8 \mathrm{mg} / \mathrm{g})$, and good adsorption ratio $(27.59 \%)$ and showed potential as a drug carrier.

Keywords: tea residue, cellulose, ionic liquid, hydrogel, single-walled carbon nanotube oxide

\section{INTRODUCTION}

The production and consumption of tea is estimated to increase in the next decade to satisfy the increase in demand for tea in developing countries, e.g., India and China. In 2016, tea production all over the world increased and exceeded 5.7 million tons. Every year, a large amount of tea residue is produced after consumption of various kinds of tea. It is an interesting and urgent issue to utilize low-value tea residue. Recently, cellulose abstracted from the waste of various fruits and vegetables, e.g., pineapple peel and bamboo shoot, has been used to prepare composite hydrogels (Dai and Huang, 2016, 2017a; Liu and Huang, 2016). Cellulose, the major component of tea residue, is a linear chain polymer composed of $\beta$-D-glucopyranose units and linked by $\beta$-1,4-glycosidic bonds and contains massive intra- and inter-molecular hydrogen bonding (Klemm et al., 2005). Cellulose has advantages of low cost and of being non-toxic, renewable, biocompatible, modifiable, and biodegradable, but it is too insoluble in most solvents to be applied in an industry because of intra-molecular and inter-molecular hydrogen bonds (Dai and Huang, 2017b). Since ionic liquids were found to be efficient solvents for cellulose at room temperature (Rogers and Seddon, 2003), a lot of them, e.g., 1-allyl-3-methylimidazolium chloride, 1-butyl-3-methylimidazolium chloride, and 1-ethyl-3-methylimidazolium chloride, were applied to process cellulose and prepare cellulose hydrogels (Wu et al., 2004; Hu et al., 2013). Cellulose-based hydrogels are suitable for embedding 
and immobilizing some functional components due to their net structure (Bardi and Koutinas, 1994; Richins et al., 2000; Francotte and Huynh, 2002). Single-walled carbon nanotubes are graphite-carbon isomers with more complex structures (Rebelo et al., 2016) and related properties for diverse applications. Because of high surface areas and special structures, single-walled carbon nanotubes can enhance solubilization and delivery of curcumin (Yuan et al., 2016), efficiently eliminate toxic phenol (Dehghani et al., 2016), sensitively detect aflatoxin B1 (Zhang et al., 2016), and so on.

In this study, we prepared composite hydrogels with singlewalled carbon nanotube oxides (SWNTs) and tea residue cellulose mixed in 1-allyl-3-methylimidazolium chloride. The single-walled carbon nanotube oxides/tea cellulose hydrogels (TCH-SWNTs) were characterized by Fourier transform infrared (FTIR), x-ray diffraction (XRD), texture profile analysis (TPA), and thermogravimetric analysis (TGA). Methylene blue was used as a drug molecule model to investigate the adsorption properties, e.g., capacity, ratio, and kinetics, of TCH-SWNTs.

\section{MATERIALS AND METHODS}

\section{Materials and Reagents}

Oolong tea leaf was obtained from South China Agricultural University. Single-walled carbon nanotube oxide (SWNTs) was purchased from Guangzhou Feibo Co., Ltd., Guangzhou, China. We purchased 1-allyl-3-methylimidazolium chloride [[AMim]Cl] from Shanghai Chengjie Chemical Co., Ltd., Shanghai, China. Methylene blue was purchased from Shanghai Chemical Co., Ltd., Shanghai, China.

All other chemical reagents used in this study were of analytical grade.

\section{Tea Cellulose Extraction}

Tea cellulose was extracted from tea residue according to the method of $\mathrm{Hu}$ ( $\mathrm{Hu}$ et al., 2010). Oolong tea leaves were immersed in $90^{\circ} \mathrm{C}$ deionized water for $30 \mathrm{~min}$, and this process was repeated three times to simulate tea beverage processing. After filtration and drying at $60^{\circ} \mathrm{C}$, the tea residue was ground to powder and sifted through a 60 -mesh sieve. The obtained tea residue powder was processed by the following four steps: first, degreasing with petroleum ether at a ratio of 1:10 $(\mathrm{g} / \mathrm{ml})$ for $2 \mathrm{~h}$; second, depigmentation with acetone at a ratio of $1: 10(\mathrm{~g} / \mathrm{ml})$ for $2 \mathrm{~h}$; third, delignification with a $\mathrm{pH} 4$ sodium chlorite solution at a ratio of $1: 20(\mathrm{~g} / \mathrm{ml})$ at $75^{\circ} \mathrm{C}$ for $2 \mathrm{~h}$;. and finally, removal of semi-cellulose with a potassium hydroxide solution $(10 \%, \mathrm{w} / \mathrm{v})$ at a ratio of $1: 20(\mathrm{~g} / \mathrm{ml})$ for $10 \mathrm{~h}$. After being washed in turns with deionized water and ethanol $(95 \%, v / v)$ until the filtrate became neutral, the tea cellulose was dried at $60^{\circ} \mathrm{C}$ and became available for the preparation of hydrogels.

\section{Hydrogels Preparation}

The preparation process of the hydrogels is shown in Figure 1. TCH-SWNTs were prepared according to the method of Kadokawa (Kadokawa et al., 2008, 2009). The tea cellulose (0.5 g) and $[\mathrm{AMim}] \mathrm{Cl}(10 \mathrm{~g})$ were mixed in a test tube and stirred at $100^{\circ} \mathrm{C}$ for $5 \mathrm{~h}$. In accordance with the formula of the samples, as shown in Figure 1, a certain amount of SWNTs was added and stirred at $100^{\circ} \mathrm{C}$ for $5 \mathrm{~h}$ until they fully dispersed. Subsequently, the viscous mixture in the test tube was poured into a petri dish to spread out. The resulting mixture was slowly immersed into deionized water to form composite hydrogel after cooling down to room temperature. TCH-SWNTs were dried using a freeze dryer for subsequent characterization analysis and adsorption

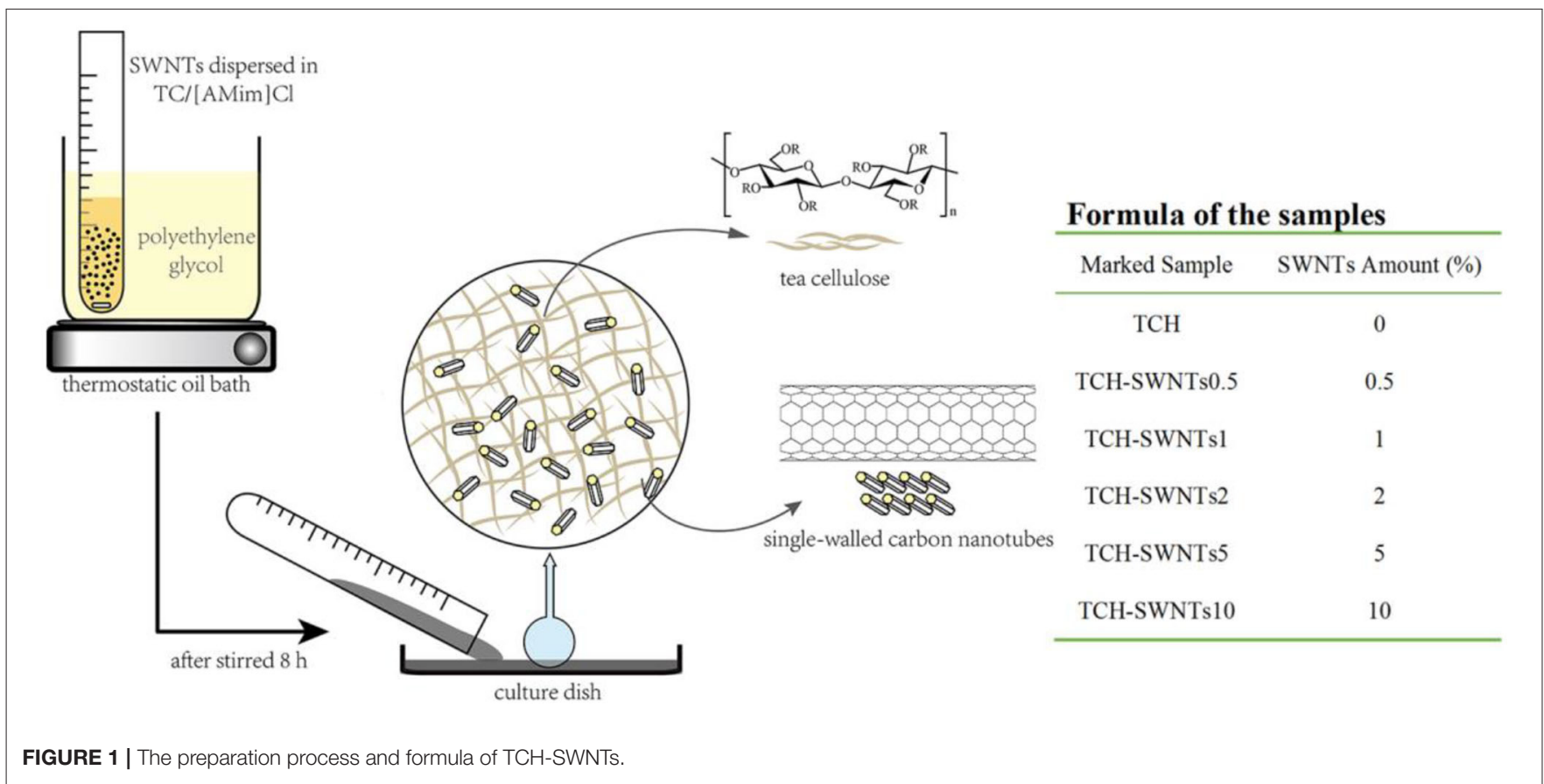


experiments. The TCH without SWNTs (TCH) was processed the same way and was used as the comparison sample.

\section{Characterization}

The FTIR spectra were recorded using a Fourier-transform infrared spectroscope (VERTEX-33, Bruker, Berlin, Germany) from 4,000 to $400 \mathrm{~cm}^{-1}$ at a resolution of $2 \mathrm{~cm}^{-1}$ (Lin et al., 2016). The XRD patterns were measured using an $\mathrm{x}$ ray diffractometer (D8 ADVANCE, Bruker, Berlin, Germany) in the region of the diffraction angle $(2 \theta)$ from 4 to $60^{\circ}$, in which the step length of scanning was $0.04^{\circ}$, and the scanning velocity was 38.4 s/step. $\mathrm{Cu} \mathrm{Ka}(\lambda=1.5406 \AA)$ was used at $30 \mathrm{~mA} 40 \mathrm{kV}$. TGA was performed and recorded using a thermobalance instrument (TGA-Q500, TA Instruments, New Castle, DE, USA) from 30 to $600^{\circ} \mathrm{C}$ at a heating rate of $20^{\circ} \mathrm{C} / \mathrm{min}$ in a $\mathrm{N}_{2}$ atmosphere. The texture profiles of the hydrogels, e.g., cohesiveness, fracturability, gumminess, hardness, resilience, and springiness, were characterized using a texture analyzer (TAXT2i, Stable Microsystems, Surrey, UK) according to the method of $\mathrm{Hu}$ (Hu et al., 2010). After being sheared to adiameter of $2.5 \mathrm{~cm}$ and a thickness of $0.8 \mathrm{~cm}$, the hydrogel sample was subjected to two-cycle compression to $30 \%$ of the initial thickness at 5 $\mathrm{mm} / \mathrm{s}$ pre-speed, $1 \mathrm{~mm} / \mathrm{s}$ cross-head speed, and $5 \mathrm{~mm} / \mathrm{s}$ postspeed.

\section{Adsorption Experiments}

As the drug model, methylene blue was used to investigate the adsorption capacity and adsorption rate of the hydrogels. TCH-SWNT $(0.05 \mathrm{~g})$ was immersed in the solution of methylene blue $(100 \mathrm{mg} / \mathrm{L}, 25 \mathrm{ml})$. The absorption value $(665 \mathrm{~nm})$ of the methylene blue solution was recorded using a spectrophotometer (UV-1800, Shimadzu, Tokyo, Japan) at a given time. The remaining methylene blue content in the solution was estimated using the regression equation $(y=0.232 x-0.029)$ derived from the concentration of methylene blue standard solution $(1,2,3,4$, and $5 \mathrm{mg} / \mathrm{L}$ ) and its absorption value.

Adsorption rate $\left(R_{e}\right)$ and adsorption capacity $\left(Q_{e}\right)$ were calculated according to the following equations (Kannan and Sundaram, 2001; Hameed et al., 2007):

$$
\begin{array}{r}
Q_{c}=\frac{c_{o}-c_{t}}{m} \times v \\
R_{c}=\left(1-\frac{c_{t}}{c_{o}}\right) \times 100 \%
\end{array}
$$

where $c_{0}$ and $c_{t}$ are the methylene blue concentrations at the initial time and a given time, respectively, $m$ is the weight of the prepared composite hydrogel sample, and $V$ is the volume of the methylene blue solution.
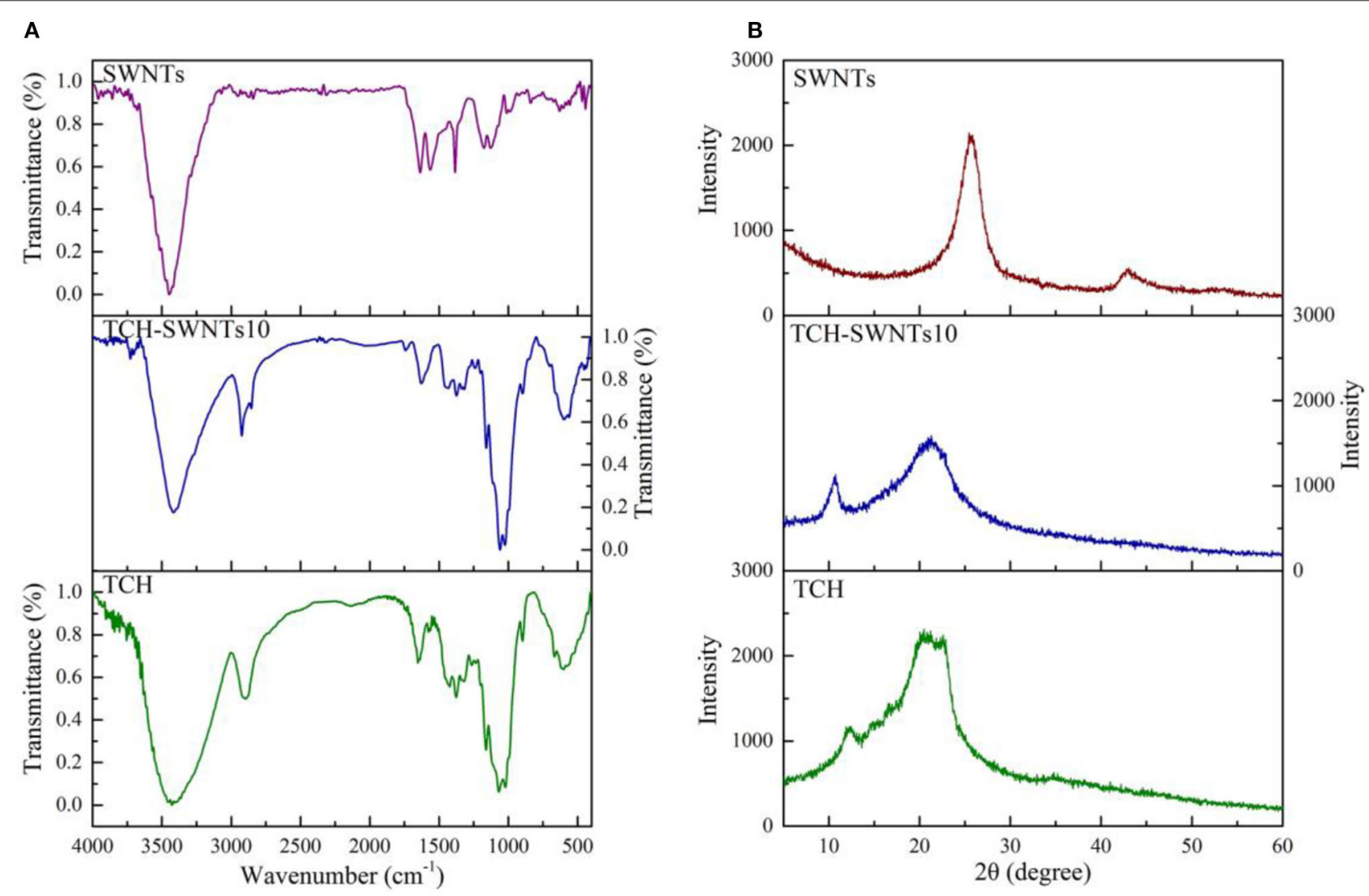

FIGURE 2 | (A) FTIR and (B) XRD spectra of SWNTs, TCH-SWNTs10, and TCH. 


\section{Statistical Analysis}

Data statistics and significance analysis were processed using Minitab (Version 17.1.0, Minitab Inc., State College, PA, USA). The probability value $p<0.05$ represented significant difference, and the probability value $p<0.01$ represented extremely significant difference.

\section{RESULTS AND DISCUSSION FTIR and XRD Analysis}

The FTIR spectra of SWNTs, TCH, and TCH-SWNTs10 are shown in Figure 2A. For SWNTs, the characteristic peak at $3,445 \mathrm{~cm}^{-1}$ was assigned to the stretching vibration of the O$\mathrm{H}$ groups. The characteristic peak at $1,630 \mathrm{~cm}^{-1}$ was due to the stretching vibration of the $\mathrm{C}-\mathrm{C}$ groups in the carbon skeleton of SWNTs (Gutierrez et al., 2017). The characteristic peaks at
2,950 and $2,854 \mathrm{~cm}^{-1}$ were relative to the stretching vibration and deformation vibration of the $\mathrm{C}-\mathrm{H}$ groups, suggesting an increase in $\mathrm{sp}^{3}$ carbon atom on the surface of SWNTs (Liang et al., 2004). The characteristic peaks at 1,610, 1,560, and $1,320 \mathrm{~cm}^{-1}$ indicated that SWNTs contain abundant oxygroups, e.g., carboxy $(\mathrm{COOH})$, hydroxy $(\mathrm{O}-\mathrm{H})$, and carbonyl $(\mathrm{C}=\mathrm{O})$ (Gutierrez et al., 2017). For TCH, the characteristic peaks at 2,919 , and $3,411 \mathrm{~cm}^{-1}$ were assigned to stretching vibration of the $\mathrm{C}-\mathrm{H}$ groups in the methyl in the cellulose and the stretching vibration of $\mathrm{O}-\mathrm{H}$ groups in the cellulose molecule chain (Peng et al., 2009). The intense peaks at 1,049 and $1,161 \mathrm{~cm}^{-1}$ were assigned to the stretching vibrations of the C-C and C-O groups (Kačuráková et al., 1994; Sun et al., 2002). The vibration of the $\beta$-glycosides bond was at $892 \mathrm{~cm}^{-1}$. For TCH-SWNTs10, the FTIR spectra are similar to those of $\mathrm{TCH}$, but the characteristic peaks at 2,950 and $2,854 \mathrm{~cm}^{-1}$

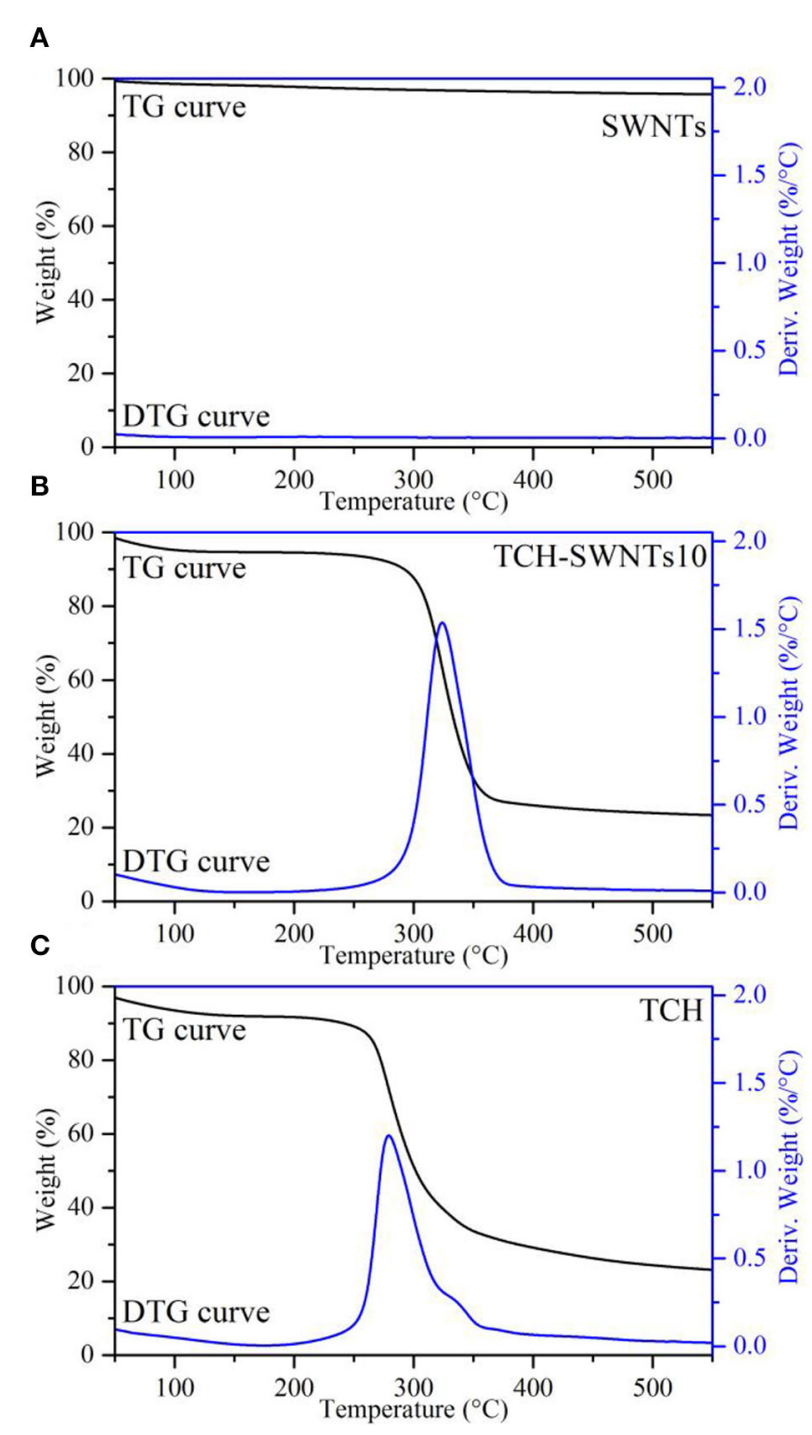

FIGURE 3 | TG and DTG curves of (A) SWNTs, (B) TCH-SWNTs10, and (C) $\mathrm{TCH}$.

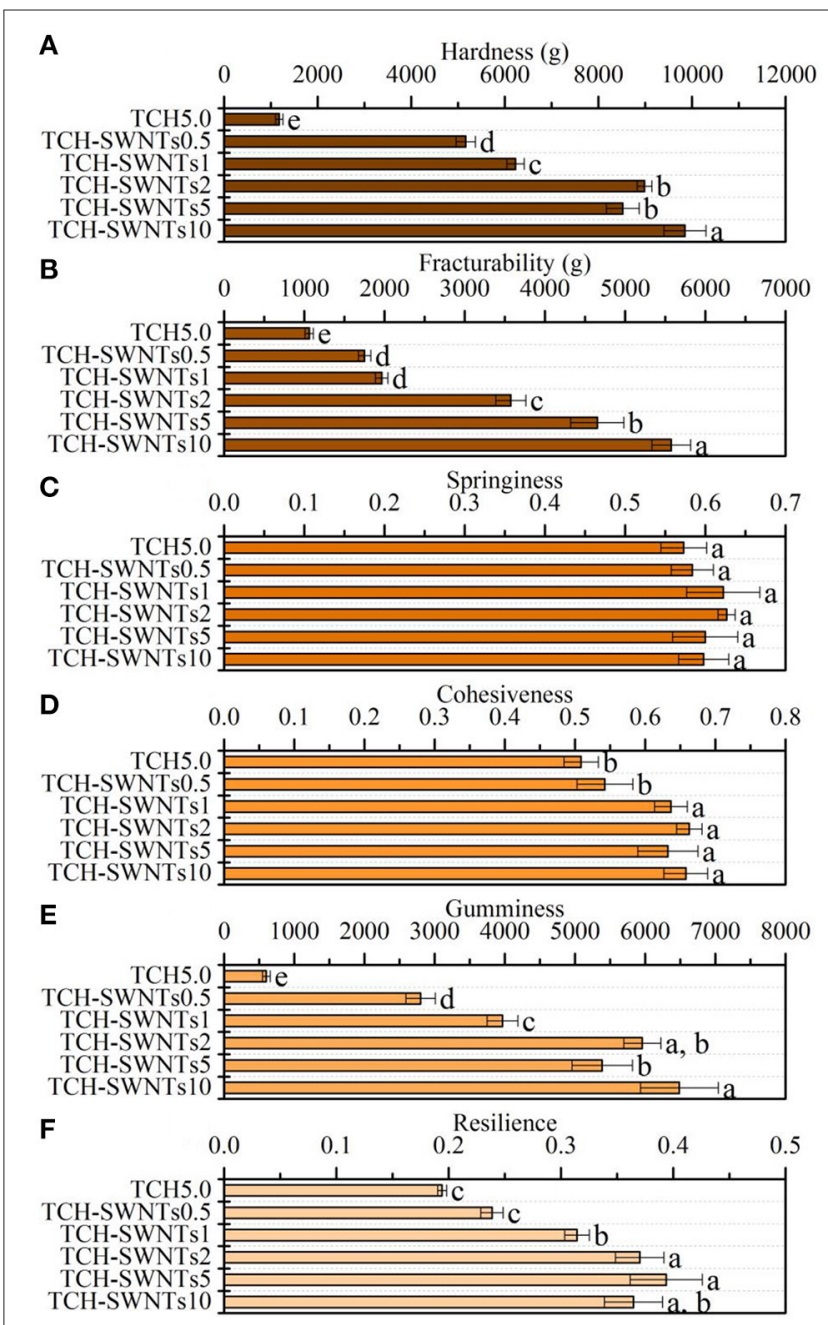

FIGURE 4 | (A) Hardness, (B) fracturability, (C) springiness, (D) cohesiveness, (E) gumminess, and (F) resilience of TCH, TCH-SWNTs.5, TCH-SWNTs1, TCH-SWNTs2, TCH-SWNTs5, and TCH-SWNTs10. Each value was expressed as mean \pm standard deviation. Bars marked with different letters represented significant differences between the values $(p<0.05)$. 


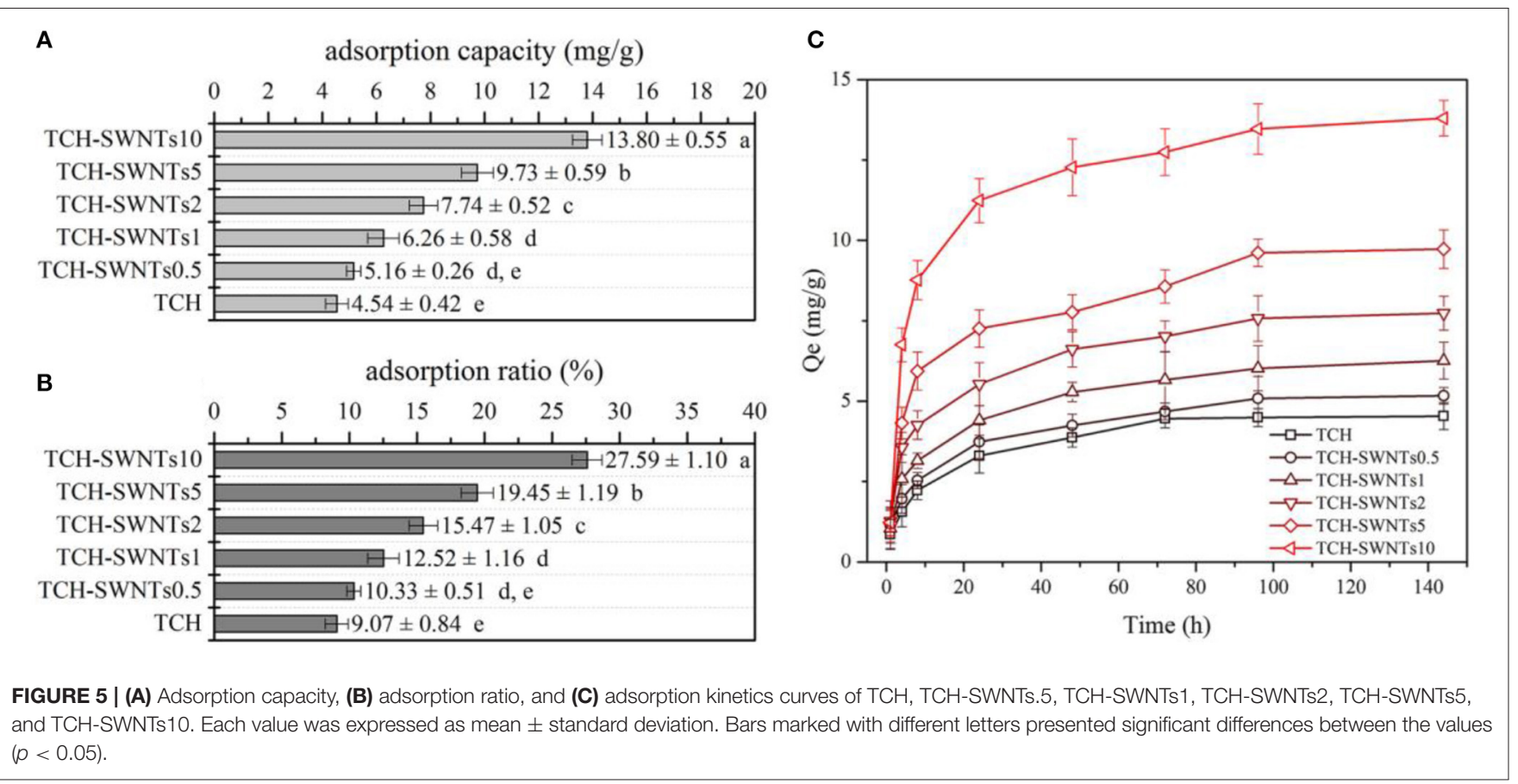

were clearly enhanced due to the vibration of the $\mathrm{C}-\mathrm{H}$ groups on SWNTs.

The XRD patterns of SWNTs, TCH, and TCH-SWNTs10 are shown in Figure 2B. For SWNTs, an intensive diffraction peak at about $2 \theta=25.5^{\circ}$ and a weak diffraction peak at about $2 \theta=43^{\circ}$ suggested that SWNTs were composed of a sixmember carbon ring structure (Han and Zettl, 2003; Liu et al., 2012). For TCH, a broad diffraction peak at about $2 \theta=21^{\circ}$ and a narrowed diffraction peak at about $2 \theta=12^{\circ}$ suggested the crystal structure of cellulose I (Chen et al., 2011). For TCH-SWNTs10, the diffraction peaks of SWNTs were hardly observed, and the diffraction peak of $\mathrm{TCH}$ at $2 \theta=21.0^{\circ}$ was decreased, suggesting that the composite hydrogels with SWNTs became more amorphous than $\mathrm{TCH}$. The decrease in crystallinity of TCH-SWNTs10 may be due to the higher non-uniform content in cellulose chains caused by the insertion of SWNTs (Vasconcellos et al., 2011).

\section{TGA Analysis}

The TGA and differential thermogravimetric (DTG) curves of SWNTs, TCH, and TCH-SWNTs10 are shown in Figure 3. The TGA curves show the accumulation of weight loss in the sample, whereas the DTG curves are first-order derivatives of the TGA curves and describe the changes in the temperature-dependent quality of the samples (El-Sayed et al., 2011).

As observed in Figure 3A, SWNTs showed good resistance to thermal shock. Due to water evaporation, the weight of SWNTs decreased by only $4.4 \%$ until the highest temperature of $600^{\circ} \mathrm{C}$ of the experiment was reached, suggesting that SWNTs are a kind of heat-resistant material (Janas and Koziol, 2013). Two weight loss steps were obviously observed from the beginning to $100^{\circ} \mathrm{C}$ and from 250 to $400^{\circ} \mathrm{C}$ in the TGA curve of $\mathrm{TCH}$, as shown in Figure 3C. Because of water evaporation, $8 \%$ of the weight was lost in the first step, whereas $66 \%$ of the weight was lost in the second step due to thermal decomposition of the sample. As shown in the DTG curve of TCH, a sharp peak was observed at around $280^{\circ} \mathrm{C}$ accompanied by $1.2 \% /{ }^{\circ} \mathrm{C}$ of derivative weight loss (deriv. weight). The TGA curve of TCH-SWNTs in Figure 3B was similar to that of TCH. Weight loss of 5 and $67 \%$ was observed in the first and second steps, respectively. The DTG curve of TCH-SWNTs showed a sharp peak at about $323^{\circ} \mathrm{C}$ along with $1.5 \% /{ }^{\circ} \mathrm{C}$ deriv. weight loss. The upshift in decomposition temperature, from 280 to $323^{\circ} \mathrm{C}$, and increase in deriv. weight in TCH-SWNTs10, from 1.2 to $1.5 \% /{ }^{\circ} \mathrm{C}$, indicated that the addition of SWNTs into the TCH could improve the thermal stability of the sample.

\section{Texture Profiles Analysis}

The texture profiles of the hydrogels prepared from tea cellulose with different contents of SWNTs are shown in Figure 4. With the increase in the amount of SWNTs, the prepared hydrogels exhibited different degrees of differences in cohesiveness, fracturability, gumminess, hardness, resilience, and springiness. It was observed that TCH-SWNTs had remarkably greater hardness (Figure 4A), fracturability (Figure 4B), gumminess (Figure 4E), and resilience (Figure 4F) than the undoped TCH, i.e., the texture parameters were further enhanced with an increase in the amount of SWNTs. As an extreme instance, the hardness, fracturability, gumminess, and resilience values of TCH-SWNTs10 were $8.4,5.3,10.8$, and 1.9 times, respectively, higher than those of TCH. Nevertheless, the springiness (Figure 4C) and cohesiveness (Figure 4D) of the hydrogels showed only a slight difference with the addition of SWNTs. 
A

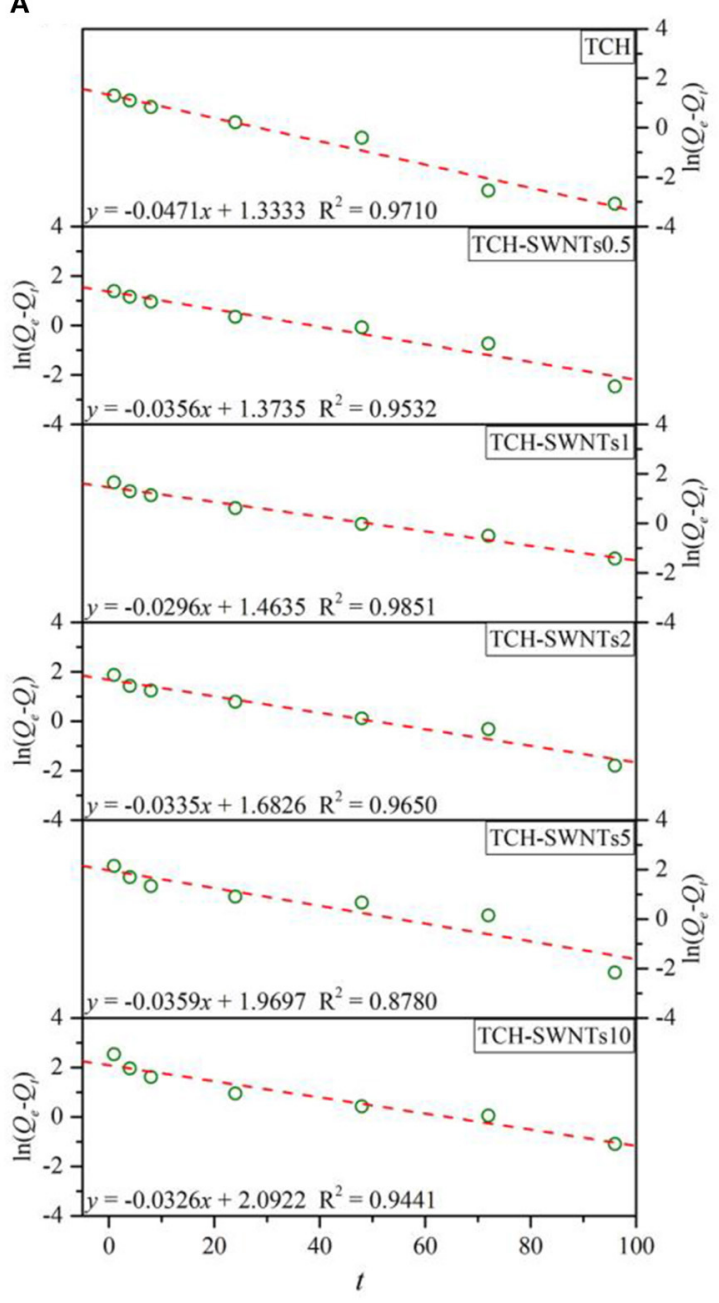

B

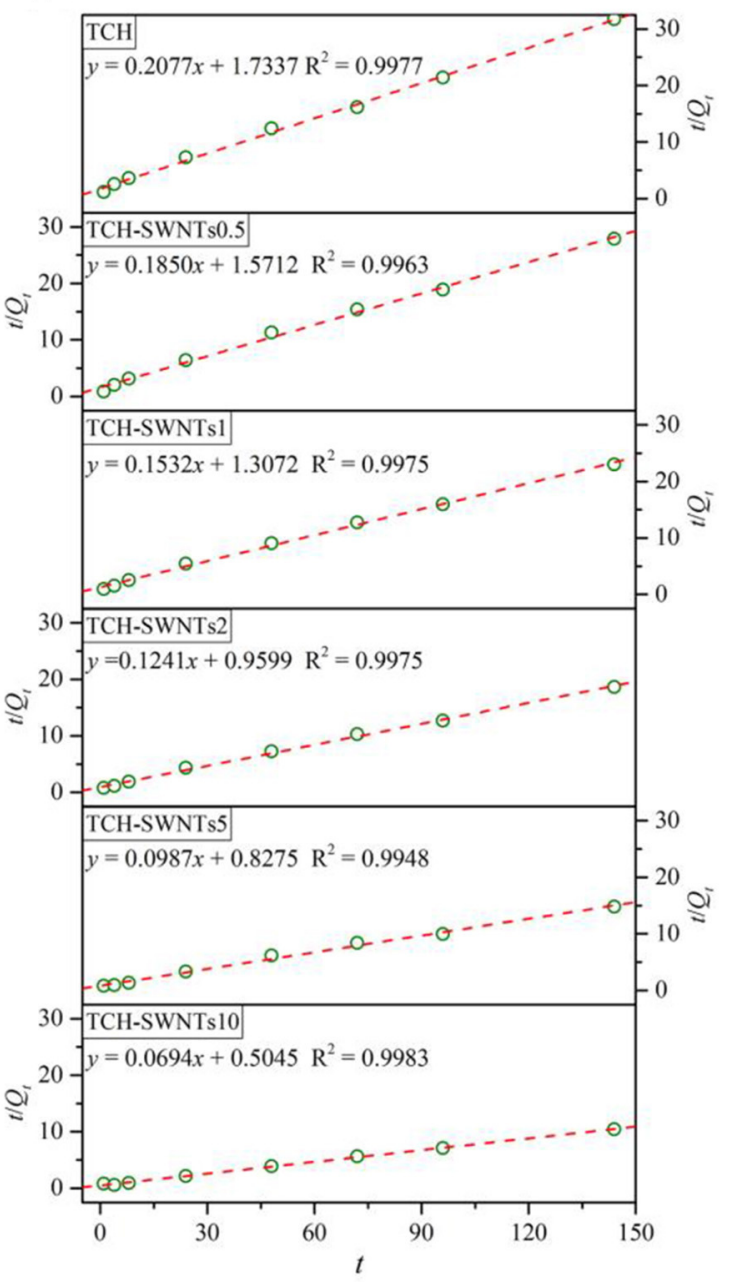

FIGURE 6 | Absorption models for the absorption of methylene blue for (A) the pseudo-first-order model and (B) the pseudo-second-order model.

These changes in texture profile parameters may be due to the hydrogen bonds between the hydroxy groups on the cellulose chain and oxygen-containing groups on the skeleton of SWNTs, e.g., $-\mathrm{COOH}$ and $-\mathrm{OH}$, which improved the interfacial adhesion of the composite hydrogels. Besides, SWNTs ran through the tea cellulose hydrogel network irregularly, dispersed stress transmission, and reinforced energy dissipation.

\section{Methylene Blue Adsorption}

As a heterocyclic aromatic chemical compound, methylene blue can be used as medication and dyestuff, and it tends to attract negative particles (Jin et al., 2008). Figure 5 shows the adsorption capacity, adsorption ratio, and adsorption kinetics curves of the prepared composite hydrogels. It was obviously observed that TCH-SWNTs had greater adsorption capacity than TCH (Figure 5A). With the increase in the amount of SWNTs, the adsorption capacity of TCH-SWNTs improved remarkably, e.g., the adsorption capacity of TCH-SWNTs10 was about three times higher than that of TCH. The changes in the adsorption ratio of the prepared composite hydrogels were similar to those in the adsorption ratio (Figure 5B). After immersion in the methylene blue solution for 6 days ( $144 \mathrm{~h}$ ) to achieve adsorption balance, TCH exhibited a maximum adsorption ratio of $9.07 \%$, whereas TCH-SWNTs10, TCH-SWNTs5, TCH-SWNTs2, TCHSWNTs1, and TCH-SWNTs.5 exhibited maximum adsorption ratios of $27.59,19.45,15.47,12.52$, and $10.33 \%$, respectively. The adsorption capacities of TCH-SWNTs10, TCH-SWNTs5, TCH-SWNTs2, TCH-SWNTs1, TCH-SWNTs.5, and TCH were calculated to be $13.8,9.73,7.74,6.26,5.16$, and $4.5 \mathrm{mg} / \mathrm{g}$, respectively. The improvement in adsorption capacity and adsorption ratio may be due to a large number of anionic groups, e.g., $-\mathrm{COO}^{-}$and $-\mathrm{O}^{-}$, in the skeleton of SWNTs. Moreover, it was observed from the adsorption kinetics curves (Figure 5C) that in the first $24 \mathrm{~h}$, the adsorption capacity growth was rapid but then tended to flatten.

Generally, the adsorption process consisted of two processes, i.e., mass transfer and mass adsorption, and could be described 
and explained by the pseudo-first-order model or the pseudosecond-order model (Ho and McKay, 1999; Azizian, 2004; Foo and Hameed, 2010).

The pseudo-first-order model assuming a change in adsorption capacity with respect to time is a first-order relationship, and its integral equation is expressed as

$$
\ln \left(Q_{c}-Q_{t}\right)=\ln \left(Q_{c}-k_{1} t\right)
$$

where $t$ is adsorption time $(\mathrm{h}), Q_{e}$ is equilibrium adsorption capacity $(\mathrm{mg} / \mathrm{g}), Q_{t}$ is adsorption capacity at a given time $(\mathrm{mg} / \mathrm{g})$, and $k_{1}$ is the rate constant of apparent adsorption of the pseudofirst-order model $\left(\mathrm{h}^{-1}\right)$.

The pseudo-second-order model assuming a change in adsorption capacity with respect to time is a first-order relationship, and its integral equation is expressed as

$$
\frac{t}{Q_{t}}=\frac{1}{k_{2} Q_{e}^{2}}+\frac{t}{Q_{e}}
$$

where $t$ is adsorption time $(\mathrm{h}), Q_{e}$ is equilibrium adsorption capacity $(\mathrm{mg} / \mathrm{g}), Q_{t}$ is adsorption capacity at a given time $(\mathrm{mg} / \mathrm{g})$, and $k_{2}$ is the rate constant of apparent adsorption of the pseudosecond-order model $[\mathrm{g} /(\mathrm{mg} \cdot \mathrm{h})]$.

Figure 6 shows the linear plot of $\ln \left(Q_{e}-Q_{t}\right)$ vs. $t$ for the pseudo-first-order model and $t / Q_{t}$ vs. $t$ for the pseudo-secondorder model for absorption of methylene blue in the prepared hydrogels.

It is observed from Figure $\mathbf{6}$ that the experimental absorption data of all prepared hydrogels fitted well with the pseudosecond-order model. The values of the determination coefficient, i.e., $R^{2}$, of the pseudo-second-order model of TCH, TCHSWNTs0.5, TCH-SWNTs1, TCH-SWNTs2, TCH-SWNTs5, and TCH-SWNTs 10 were $0.9977,0.9963,0.9975,0.9975,0.9948$, and 0.9983 , respectively, which were higher than those of the pseudofirst-order model. Furthermore, with the increase in the amount of SWNTs, the rate constants of apparent adsorption of the pseudo-second-order model exhibited a declining trend, so the $k_{2}$ values of TCH, TCH-SWNTs.5, TCH-SWNTs1, TCH-SWNTs2,
TCH-SWNTs5, and TCH-SWNTs10 were calculated to be 0.0249 , $0.0218,0.0179,0.0161,0.0118$, and $1.0095 \mathrm{~g} /(\mathrm{mg} \cdot \mathrm{h})$, respectively. Besides, the values of predicted adsorption capacity, i.e., $Q_{e}$, of the pseudo-second-order model were 4.82, 5.41, 6.53, 8.06, 10.14 , and $14.41 \mathrm{mg} / \mathrm{g}$, which were closer to experimental values (Figure 5A).

According to the three reasons mentioned above, the kinetic adsorption behaviors of the prepared hydrogels could be described and evaluated by the pseudo-second-order model, which suggested that chemical adsorption dominated the adsorption process of TCH-SWNTs.

\section{CONCLUSION}

Characterization analysis of XRD and FTIR suggested successful preparation of hydrogels from tea residue cellulose with the addition of SWNTs in 1-allyl-3-methylimidazolium chloride. Observed from the results of TGA and TPA analysis, the thermal stability and textural properties of the composite hydrogels improved with an increase in the amount of SWNTs. The composite hydrogels exhibited a chemisorption behavior that was well-described by the pseudo-second-order model.

\section{DATA AVAILABILITY STATEMENT}

The raw data supporting the conclusions of this article will be made available by the authors, without undue reservation.

\section{AUTHOR CONTRIBUTIONS}

ZL did the most parts of experiments, analyzed data, and wrote this paper. DL provided an idea and polished up the article.

\section{ACKNOWLEDGMENTS}

The authors would like to thank the Key Platforms and Research Projects of Guangdong Province in 2017 (2017GkQNCX025) for their financial support that makes this study possible.

\section{REFERENCES}

Azizian, S. (2004). Kinetic models of sorption: a theoretical analysis. J. Colloid Interface Sci. 276, 47-52. doi: 10.1016/j.jcis.2004.03.048

Bardi, E., and Koutinas, A. (1994). Immobilization of yeast on delignified cellulosic material for room temperature and low-temperature wine making. J. Agric. Food Chem. 42, 221-226. doi: 10.1021/jf00037a040

Chen, W., Yu, H., Liu, Y., Chen, P., Zhang, M., and Hai, Y. (2011). Individualization of cellulose nanofibers from wood using high-intensity ultrasonication combined with chemical pretreatments. Carbohydr. Polym. 83, 1804-1811. doi: 10.1016/j.carbpol.2010.10.040

Dai, H., and Huang, H. (2016). Modified pineapple peel cellulose hydrogels embedded with sepia ink for effective removal of methylene blue. Carbohydr. Polym. 148, 1-10. doi: 10.1016/j.carbpol.2016.04.040

Dai, H., and Huang, H. (2017a). Enhanced swelling and responsive properties of pineapple peel carboxymethyl cellulose-g-poly. (acrylic acid-co-acrylamide) superabsorbent hydrogel by the introduction of

carclazyte. J. Agric. Food Chem. 65, 565-574. doi: 10.1021/acs.jafc.6b 04899

Dai, H., and Huang, H. (2017b). Synthesis, characterization and properties of pineapple peel cellulose-g-acrylic acid hydrogel loaded with kaolin and sepia ink. Cellulose 24, 69-84. doi: 10.1007/s10570-016-1101-0

Dehghani, M. H., Mostofi, M., Alimohammadi, M., McKay, G., Yetilmezsoy, K., Albadarin, A. B., et al. (2016). High-performance removal of toxic phenol by single-walled and multi-walled carbon nanotubes: kinetics, adsorption, mechanism and optimization studies. J. Ind. Eng. Chem. 35, 63-74 doi: 10.1016/j.jiec.2015.12.010

El-Sayed, S., Mahmoud, K., Fatah, A., and Hassen, A. (2011). DSC, TGA and dielectric properties of carboxymethyl cellulose/polyvinyl alcohol blends. Phys $B$ Condens. Matter 406, 4068-4076. doi: 10.1016/j.physb.2011.07.050

Foo, K. Y., and Hameed, B. H. (2010). Insights into the modeling of adsorption isotherm systems. Chem. Eng. J. 156, 2-10. doi: 10.1016/j.cej.2009.09.013

Francotte, E., and Huynh, D. (2002). Immobilized halogenophenylcarbamate derivatives of cellulose as novel stationary phases for 
enantioselective drug analysis. J. Pharm. Biomed. Anal. 27, 421-429. doi: 10.1016/S0731-7085(01)00568-4

Gutierrez, F. A., Gonzalez-Dominguez, J. M., Ansón-Casaos, A., HernándezFerrer, J., Rubianes, M. D., Martínez, M. T., et al. (2017). Single-walled carbon nanotubes covalently functionalized with cysteine: a new alternative for the highly sensitive and selective Cd. (II) quantification. Sens. Actuat. B Chem. 249, 506-514. doi: 10.1016/j.snb.2017.04.026

Hameed, B., Din, A. M., and Ahmad, A. (2007). Adsorption of methylene blue onto bamboo-based activated carbon: kinetics and equilibrium studies. J. Hazard. Mater. 141, 819-825. doi: 10.1016/j.jhazmat.2006.07.049

Han, W. Q., and Zettl, A. (2003). Coating single-walled carbon nanotubes with tin oxide. Nano Lett. 3, 681-683. doi: 10.1021/nl034142d

Ho, Y. S., and McKay, G. (1999). Pseudo-second order model for sorption processes. Process Biochem. 34, 451-465. doi: 10.1016/S0032-9592(98)00112-5

$\mathrm{Hu}, \mathrm{X} ., \mathrm{Hu}, \mathrm{K}$. , Zeng, L., Zhao, M., and Huang, H. (2010). Hydrogels prepared from pineapple peel cellulose using ionic liquid and their characterization and primary sodium salicylate release study. Carbohydr. Polym. 82, 62-68. doi: 10.1016/j.carbpol.2010.04.023

$\mathrm{Hu}, \mathrm{X}$., Wang, J., and Huang, H. (2013). Impacts of some macromolecules on the characteristics of hydrogels prepared from pineapple peel cellulose using ionic liquid. Cellulose 20, 2923-2933. doi: 10.1007/s10570-013-0075-4

Janas, D., and Koziol, K. K. (2013). Rapid electrothermal response of high-temperature carbon nanotube film heaters. Carbon 59, 457-463. doi: 10.1016/j.carbon.2013.03.039

Jin, X., Jiang, M., Shan, X., Pei, Z., and Chen, Z. (2008). Adsorption of methylene blue and orange II onto unmodified and surfactant-modified zeolite. J. Colloid Interface Sci. 328, 243-247. doi: 10.1016/j.jcis.2008.08.066

Kačuráková, M., Ebringerova, A., Hirsch, J., and Hromadkova, Z. (1994). Infrared study of arabinoxylans. J. Sci. Food Agric. 66, 423-427. doi: 10.1002/jsfa.2740660323

Kadokawa, J., Murakami, M., and Kaneko, Y. (2008). A facile preparation of gel materials from a solution of cellulose in ionic liquid. Carbohydr. Res. 343, 769-772. doi: 10.1016/j.carres.2008.01.017

Kadokawa, J., Murakami, M., Takegawa, A., and Kaneko, Y. (2009). Preparation of cellulose-starch composite gel and fibrous material from a mixture of the polysaccharides in ionic liquid. Carbohydr. Polym. 75, 180-183. doi: 10.1016/j.carbpol.2008.07.021

Kannan, N., and Sundaram, M. M. (2001). Kinetics and mechanism of removal of methylene blue by adsorption on various carbons-a comparative study. Dyes Pigmen. 51, 25-40. doi: 10.1016/S0143-7208(01)00056-0

Klemm, D., Heublein, B., Fink, H. P., and Bohn, A. (2005). Cellulose: fascinating biopolymer and sustainable raw material. Angew. Chem. Int. Ed. 44, 3358-3393. doi: 10.1002/anie.200460587

Liang, F., Sadana, A. K., Peera, A., Chattopadhyay, J., Gu, Z., Huage, R. H., et al. (2004). A convenient route to functionalized carbon nanotubes. Nano Lett. 4, 1257-1260. doi: 10.1021/nl049428c

Lin, Z., Liao, W., and Ren, J. (2016). Physicochemical characterization of a polysaccharide fraction from Platycladus orientalis. (L.) franco and its macrophage immunomodulatory and anti-hepatitis $B$ virus activities. J. Agric. Food Chem. 64, 5813-5823. doi: 10.1021/acs.jafc.6b 01387
Liu, H., Huang, J., Li, X., Liu, J., and Zhang, Y. (2012). One-step hydrothermal synthesis of flower-like $\mathrm{SnO} 2 /$ carbon nanotubes composite and its electrochemical properties. J. Sol Gel Sci. Technol. 63, 569-572. doi: 10.1007/s10971-012-2776-9

Liu, Z., and Huang, H. (2016). Preparation and characterization of cellulose composite hydrogels from tea residue and carbohydrate additives. Carbohydr. Polym. 147, 226-233. doi: 10.1016/j.carbpol.2016.03.100

Peng, F., Ren, J. L., Xu, F., Bian, J., Peng, P., and Sun, R. C. (2009). Comparative study of hemicelluloses obtained by graded ethanol precipitation from sugarcane bagasse. J. Agric. Food Chem. 57, 6305-6317. doi: 10.1021/jf900986b

Rebelo, S. L., Guedes, A., Szefczyk, M. E., Pereira, A. M., Araújoc, J. P., and Freirea, C. (2016). Progress in the Raman spectra analysis of covalently functionalized multiwalled carbon nanotubes: unraveling disorder in graphitic materials. Phys. Chem. Chem. Phys. 18, 12784-12796. doi: 10.1039/C5CP06519D

Richins, R. D., Mulchandani, A., and Chen, W. (2000). Expression, immobilization, and enzymatic characterization of cellulose-binding domainorganophosphorus hydrolase fusion enzymes. Biotechnol. Bioeng. 69, 591-596. doi: 10.1002/1097-0290(20000920)69:6<591::AID-BIT2>3.0.CO;2-X

Rogers, R. D., and Seddon, K. R. (2003). Ionic liquids-solvents of the future? Science 302, 792-793. doi: 10.1126/science.1090313

Sun, X. F., Sun, R., and Sun, J. X. (2002). Acetylation of rice straw with or without catalysts and its characterization as a natural sorbent in oil spill cleanup. J. Agric. Food Chem. 50, 6428-6433. doi: 10.1021/jf020392o

Vasconcellos, F. C., Goulart, G. A., and Beppu, M. M. (2011). Production and characterization of chitosan microparticles containing papain for controlled release applications. Powder Technol. 205, 65-70. doi: 10.1016/j.powtec.2010.08.066

Wu, J., Zhang, J., Zhang, H., He, J., Ren, Q., and Guo, M. (2004). Homogeneous acetylation of cellulose in a new ionic liquid. Biomacromolecules 5, 266-268. doi: 10.1021/bm034398d

Yuan, S., Zeng, L., Zhuang, Y., Hou, Q., and Song, M. (2016). Functionalized single-walled carbon nanotubes for the improved solubilization and delivery of curcumin. Fuller. Nanotub. Carbon Nanostructures 24, 13-19. doi: 10.1080/1536383X.2015.10 88007

Zhang, X., Li, C. R., Wang, W. C., Xue, J., Huang, Y. L., Yang, X. X., et al. (2016). A novel electrochemical immunosensor for highly sensitive detection of aflatoxin B1 in corn using single-walled carbon nanotubes/chitosan. Food Chem. 192, 197-202. doi: 10.1016/j.foodchem.2015. 06.044

Conflict of Interest: The authors declare that the research was conducted in the absence of any commercial or financial relationships that could be construed as a potential conflict of interest.

Copyright (C) $2021 \mathrm{Liu}$ and Li. This is an open-access article distributed under the terms of the Creative Commons Attribution License (CC BY). The use, distribution or reproduction in other forums is permitted, provided the original author(s) and the copyright owner(s) are credited and that the original publication in this journal is cited, in accordance with accepted academic practice. No use, distribution or reproduction is permitted which does not comply with these terms. 